\title{
Designing Environments to Enhance Physical and Psychological Benefits of Physical Activity: A Multidisciplinary Perspective
}

\author{
Eric Brymer $^{1} \cdot$ Keith Davids $^{2,3}$
}

Published online: 25 April 2016

(c) Springer International Publishing Switzerland 2016

There is increasing recognition that physical inactivity is an important global health challenge. According to relevant bodies such as the World Health Organisation, insufficient physical activity is now the fourth leading underlying cause of premature mortality, contributing to approximately 3.2 million deaths each year [1]. Substantial evidence suggests that regular physical activity is an effective preventative and rehabilitative intervention for over 30 distinct diseases or health conditions [2,3]. Indeed, a report commissioned in 2015 by the Academy of Medical Royal Colleges in the UK described physical activity as a 'miracle cure' that might provide more effective prevention and treatment than drugs for many mental and physical health conditions [4]. For example, regular physical activity can lower the risk of developing depression, anxiety, breast cancer and bowel cancer, dementia, cardiorespiratory conditions, heart disease, type 2 diabetes and stroke $[3,5$, 6], in many cases by $30 \%$ or more. Globally, there is also a substantial economic impact associated with physical activity or the lack thereof [7]. For example, in the UK the

This article is part of the Topical Collection on Designing environments to enhance physical and psychological benefits of physical activity: A multi-disciplinary perspective.

Eric Brymer

e.brymer@leedsbeckett.ac.uk

1 Institute for Sport, Physical Activity and Leisure, Leeds Beckett University, Leeds, UK

2 Sheffield Hallam University, Sheffield, UK

3 FiDi Program, University of Jyväskylä, Jyväskylä, Finland cost of insufficient physical activity was estimated at over $£ 15$ billion in 2015 [4]. In Canada, similar estimations undertaken in 2009 were US\$6.2 billion, and in China in 2007 the estimated costs were US\$6.7 billion [8].

Physical activity has also been associated with health and wellbeing outcomes beyond the pathogenic and clinical focus of protection against disease. Regular physical activity has been associated with the salutogenic approach (attending to dynamics that sponsor wellbeing, as differentiated from factors that trigger disease), enhancing various quality-of-life measures such as social and emotional wellbeing and overall engagement with life. Just one bout of physical activity has been shown to enhance positive affective outcomes [9]. Physical activity provides opportunities for improving physical, psychological and emotional wellbeing, reducing the risk of lifestyle diseases, relieving stress, increasing positive mood, enhancing life skills, reducing mental fatigue, increasing concentration and reducing the tendency for aggressive behaviour.

The significance of regular physical activity in mediating effects of lifestyle diseases has been recognised for over 5 decades, with, for example, the American Heart Association publishing physical activity recommendations in 1975. Around the same time, the UK government published their first policy paper recognising the links between physical inactivity and disease [10]. In the 1990s the UK Government set up programmes designed to educate the general public about the benefits of physical activity and promote physical activity. There are now many programmes and policies that educate about physical activity and recommend and promote physical activity around the world. However, despite the prevalence of recommendations and programmes, the World Health Organisation determined that at a global level only one person in every 
four undertakes enough physical activity [1]. Clearly, the mere provision of information to substantiate recommendations and guidelines for enhancing health through regular physical activity may not be enough. One important factor that has been generally overlooked is that the modern-day environment may not be conducive to some population groups becoming and remaining physically active. Concerns over public health issues related to physical inactivity may be addressed by designing environments that provide opportunities for different population groups to enhance physical activity levels and gain the health and wellbeing benefits of physical activity [11]. An initial step in this task is to develop a detailed theoretical account of how healthier environments might be designed to facilitate engagement of different population groups with opportunities to be meaningfully physically active. Accordingly, this multidisciplinary themed issue focuses attention on the design of work spaces, community areas, playscapes, education settings and programmes of exercise, play and physical activity, predicated on a comprehensive theoretical rationale and practical application. For this purpose, this themed issue includes theoretical perspectives outlining key principles for designing environments that promote physical activity, as well as more practical perspectives demonstrating the application of these design principles. The intended outcome is for scientists, designers and healthcare practitioners to collaboratively consider how societies can move beyond the mere provision of information on health benefits of physical activity and exercise towards a more detailed understanding of how to design everyday environments that promote and invite physical activity in different population groups based on age, sex, sociocultural differences and disease status of society members.

\section{Compliance with Ethical Standards}

Funding No sources of funding were used to assist in the preparation of this preface.

Conflicts of interest Keith Davids and Eric Brymer declare that they have no conflicts of interest relevant to the content of this preface.

\section{References}

1. World Health Organisation. Physical inactivity: a global public health problem. 2009. Available at: http://www.who.int/ dietphysicalactivity/factsheet_inactivity/en/

2. Booth FW, Roberts CK, Laye MJ. Lack of exercise is a major cause of chronic diseases. Compr Physiol. 2012;2(3):1143-211.

3. Warburton DE, Nicol CW, Bredin SS. Health benefits of physical activity: the evidence. CMAJ. 2006;174(6):801-9.

4. McNally S, for the Academy of Medical Royal Colleges. Exercise: the miracle cure and the role of the doctor in promoting it. London: Academy of Medical Royal Colleges; 2015.

5. Paluska SA, Schwenk TL. Physical activity and mental health. Sports Med. 2000;29(3):167-80.

6. Carek PJ, Laibstain SE, Carek SM. Exercise for the treatment of depression and anxiety. Int J Psychiatry Med. 2011;41:15-28.

7. Pratt M, Norris J, Lobelo F, et al. The cost of physical inactivity: moving into the 21st century. Br J Sports Med. 2014;4(48):171-3.

8. Pratt M, Norris J, Lobelo F, et al. The cost of physical inactivity: moving into the 21st century. Br J Sports Med. 2014;4(48):171-3.

9. Backhouse SH, Ekkekakis P, Biddle SJH, et al. Exercise makes people feel better but people are inactive: paradox or artifact. J Sport Exerc Psychol. 2007;29:498-517.

10. Milton K, Bauman A. A critical analysis of the cycles of physical activity policy in England. Int J Behav Nutr Phys Act. 2015;12:8.

11. Ward Thompson C, Roe J, Aspinall P. Woodland improvements in deprived urban communities: What impact do they have on people's activities and quality of life? Landsc Urban Plan. 2013;118:79-89. 